\title{
Effect of Glucose Variability on Pancreatic Cancer Through Regulation of COL6AI
}

This article was published in the following Dove Press journal:

Cancer Management and Research

Qian Yu'

Zhong Zhang $\mathbb{D}^{2}$

Haijun Zhang $\mathbb{D}^{2}$

'Department of Gastroenterology, Zhongda Hospital, Medical School of Southeast University, Nanjing, Jiangsu, People's Republic of China; ${ }^{2}$ Department of Oncology, Zhongda Hospital, Medical School of Southeast University, Nanjing, Jiangsu, People's Republic of China
Correspondence: Haijun Zhang Department of Oncology, Zhongda Hospital, Medical School of Southeast University, 87 Dingjiaqiao Road, Nanjing, Jiangsu, 210009, People's Republic of China

Tel/Fax +862583272216

Email zhanghaijunseu@I63.com
Background: Pancreatic cancer (PC), a devastating cancer worldwide, remains dismal prognosis due to its clinical elusiveness, especially in relation to diabetes mellitus (DM). The study aims to investigate the effect of glucose variability on COL6A1 in PC cancer cells and the prognostic potential of COL6A1 for PC patient associated with DM.

Methods: After PC cancer cell lines of AsPC-1 and BxPC-3 were treated with hyperglycemia and hypoglycemia, Giemsa staining and Transwell chamber were performed to assay plate clone formation, migration and invasion. Expressions of COL6A1 of PC cancer cell lines under different extracellular glucose levels were detected by qRT-PCR and Western blotting. The level of COL6A1 expression in PC patients with/without DM was further observed with immunohistochemistry. The prognostic impact of COL6A1 on PC patients with DM was assessed by Kaplan-Meier survival curve analysis.

Results: Hyperglycemia promoted proliferation, migration and invasion of PC cancer cells compared with hypoglycemia. Glucose variability could regulate expression of COL6A1 in PC cancer cells, both Col6al mRNA and COL6A1 protein upregulated in cancer cells cultured with hyperglycemic than that with hypoglycemic. The level of COL6A1 expression was higher in PC patients with DM than that without DM. Besides, COL6A1 was significantly associated with the clinical prognosis of PC patients with DM, higher COL6A1 leading to lower overall survival (OS).

Conclusion: Glucose variability had effect on PC cancer cells through regulation of COL6A1. Accordingly, COL6A1 was associated with poorer prognosis in PC patients with DM.

Keywords: pancreatic cancer, diabetes mellitus, COL6A1, prognosis

\section{Introduction}

Pancreatic cancer (PC), a devastating cancer around the world, usually exists with the distinguishing features of late detection, distant metastasis, and poor prognosis. ${ }^{1}$ The 5-year survival rate is $<5 \%$ miserably in $\mathrm{PC}$ patients at an advanced stage, even in patients at an early stage still only $22 \%{ }^{2,3}$ Prognosis of $\mathrm{PC}$ remains so dismal due to its clinically elusive nature, especially its relationship with diabetes mellitus (DM). ${ }^{4,5}$

DM is associated with PC in more than $80 \%$ of the cases, ${ }^{6}$ the relationship of which is bi-directional: DM as a risk factor as well as an early manifestation of PC. ${ }^{6,7}$ In vitro hyperglycemia and peripheral insulin resistance could promote the growth of PC cancer cells. ${ }^{8}$ Patients who were newly diagnosed with DM or hyperglycemia as a high-risk group have been proposed for primary screening for PC. ${ }^{9}$ In addition, PC could affect glucose metabolism, insulin secretion, thus DM 
could develop as an early sign of PC. ${ }^{10,11} \mathrm{PC}$ is poorly vascularized, hypoxic and severely hypoglycemic in the tumor microenvironment. ${ }^{12,13}$ As a result, oscillations in extracellular glucose levels are probable to occur, especially in PC patient associated with DM. Unfortunately, to date, the biological effect of glucose variability on PC has not been fully determined. Therefore, further investigation into the molecular mechanism is required and meaningful.

Collagen, type VI, a 1 chain (COL6A1) possess an anchoring function, which plays roles in cell migration, differentiation, and embryonic development. ${ }^{14-16}$ It is significantly low-expressed in tissues such as the gastrointestinal tract, brain, and pancreas. ${ }^{17}$ However, the Col6al gene is active in tumor. ${ }^{18}$ Compared to the corresponding normal tissues, tumor tissues such as cervical cancer, prostate cancer, lung cancer, and PC, have higher expression of COL6A1. ${ }^{18-20}$ The overexpression of COL6A1 could enhance motility and metastasis of cancer cells. ${ }^{21}$ Although the potential role of COL6A1 has been described in tumors, it is still unclear in PC associated with DM.

In this connection, the purpose of this study was to investigate the effect of glucose variability on COL6A1 expression in $\mathrm{PC}$ cancer cells and the prognostic potential of COL6A1 for PC patients associated with DM.

\section{Materials and Methods}

\section{Cell Culture}

One PC cell line of AsPC-1, obtained from the Shanghai Institute of Cell Biology, Chinese Academy of Sciences, was cultured in Dulbecco's modified Eagle's medium (DMEM) at $37.0^{\circ} \mathrm{C}, 5 \% \mathrm{CO}_{2}$, supplemented with $10 \%$ heat-inactivated fetal bovine serum (FBS), $100 \mathrm{U} / \mathrm{mL}$ penicillin and $100 \mu \mathrm{g} / \mathrm{mL}$ streptomycin (Sigma-Aldrich Co., St Louis, MO, USA). The medium contained the different concentrations of $25 \mathrm{mmol} / \mathrm{L}$ and $4 \mathrm{mmol} / \mathrm{L}$ glucose to simulate hyperglycemia and hypoglycemia, respectively. Similarly, the other PC cell line of BxPC-3, purchased from the Shanghai Institute of Cell Biology, Chinese Academy of Sciences, was cultured in Roswell Park Memorial Institute (RPMI) 1640 medium (Gibco ${ }^{\circledR}$ 1640; Life Technologies, Carlsbad, CA, USA) with the concentrations of $11.1 \mathrm{mmol} / \mathrm{L}$ and $4 \mathrm{mmol} / \mathrm{L}$ glucose as hyperglycemia and hypoglycemia, respectively.

\section{Plate Clone Formation Assay}

AsPC-1 and BxPC-3 cells treated with the high or low level of glucose were sub-cultured into 60-mm Petri dishes with $5 \times 10^{2}$ cells per dish for 14 days until the visible clones occurred. Giemsa staining was carried out, and stained cells were observed and photographed. In addition, AsPC- 1 and BxPC- 3 cells $\left(2 \times 10^{2}\right.$ cells $)$ treated with the high or low level of glucose were seeded with the $100 \mathrm{~mL}$ respective conditioned medium in 96-well plates. After 24, 48 , and 72 hours, $10 \mu \mathrm{L}$ cell counting kit- 8 (CCK-8) was added to each well. Proliferation rate was determined and calculated by measuring optical density (OD) at $450 \mathrm{~nm}$. Each experiment was repeated three times independently.

\section{Cancer Cell Migration and Invasion Assays}

Transwell chamber was performed to assay cancer cell migration and invasion. Briefly, $200 \mu \mathrm{L}$ AsPC-1 and BxPC-3 cells at $2 \times 10^{4} / \mathrm{mL}$ treated with the high or low level of glucose were seeded to the upper chamber, then $500 \mu \mathrm{L}$ of plain fresh growth medium with $10 \%$ FBS was added to the lower chamber. After 24 hours, cancer cells in the upper chamber that had not migrated or invaded were removed with a cotton swab completely, then the migrated and invaded cells were fixed with $100 \%$ methanol and stained with $10 \%$ crystal violet for observation under an inverted optical microscope. Each experiment was repeated three times independently.

\section{Quantitative Real-Time Polymerase Chain Reaction (qRT-PCR)}

According to the manufacturer's protocol, the RNA extracted from AsPC-1 and BxPC-3 cells treated with the high or low level of glucose using TRIzol reagent (Life Technologies Corporation, Carlsbad, CA 92008 USA) was subsequently reverse transcribed into cDNA using random hexamers. Amplification of the transcripts involved an initial denaturation at $95^{\circ} \mathrm{C}$ for $30 \mathrm{sec}$, followed by 40 cycles at $95^{\circ} \mathrm{C}$ for $5 \mathrm{sec}, 60^{\circ} \mathrm{C}$ for $20 \mathrm{sec}$, and $72^{\circ} \mathrm{C}$ for 5 $\mathrm{sec}$ in the Light-CyclerTM480 system for qRT-PCR. Meanwhile, glyceraldehyde 3-phosphate dehydrogenase (Gapdh) was used as a standardized internal control. Each experiment was repeated three times independently. Data were calculated using the $2^{-\Delta \Delta \mathrm{Cq}}$ method. ${ }^{22}$ Detailed sequences of the primers for Col6al and Gapdh are listed in Table 1.

\section{Western Blotting}

AsPC-1 and BxPC-3 cells treated with the high or low level of glucose were lysed, and proteins were isolated, 
Table I Primers of Col6al and Gapdh

\begin{tabular}{|l|l|l|}
\hline Gene & \multicolumn{2}{|c|}{ Primer } \\
\hline Col6al & $\begin{array}{l}\text { Forward } \\
\text { Revers }\end{array}$ & $\begin{array}{l}\text { 5'-ACACCGACTGCGCTATCAAG-3' } \\
\text { 5'-CGGTCACCACAATCAGGTACTT-3' }\end{array}$ \\
\hline Gapdh & $\begin{array}{l}\text { Forward } \\
\text { Revers }\end{array}$ & $\begin{array}{l}\text { 5'-TGTGGGCATCAATGGATTTGG-3' } \\
\text { 5'-ACACCATGTATTCCGGGTCAAT-3 }\end{array}$ \\
\hline
\end{tabular}

separated by sodium dodecyl sulfate polyacrylamide gel electrophoresis and transferred on to a polyvinylidene difluoride membrane. The membranes were incubated overnight at $4^{\circ} \mathrm{C}$ with a primary anti-polyclonal antibody against COL6A1 and GAPDH (Nanjing KeyGen Biotech Co, Ltd, Nanjing, China). Washed with PBS, the membranes were then incubated with secondary antibodies of horseradish peroxidase-conjugated IgG (Nanjing KeyGen Biotech Co, Ltd, Nanjing, China). The protein bands were detected, and COL6A1 expression levels were determined after normalization using the corresponding GAPDH expression. Each experiment was repeated three times independently.

\section{Patients and Tissue Specimens}

Patients with PC confirmed by histopathology from January, 2010 to December, 2019 in Zhongda Hospital, Medical School of Southeast University were selected for this study. The patients were coincided to combine with DM according to diagnostic standard of World Health Organization (WHO). They did not receive any chemotherapy, radiotherapy, molecular targeted therapy, or immunotherapy before surgery. All patients signed informed consent. Patients were followed up on a regular basis by phone or at scheduled office visits. Paraffin-embedded tissue samples were acquired for immunohistochemistry staining. The study was approved by the ethics committee of Zhongda Hospital, Southeast University. The study protocol protected the private information of enrolled patients in accordance with the provisions of the Helsinki Declaration.

\section{Immunohistochemistry Staining}

The paraffin-embedded archival samples were cut into $4-\mu \mathrm{m}$-thick sections, and mounted on glass slides. After dewaxed in xylene, rehydrated in grade alcohol, antigen retrieval at $120^{\circ} \mathrm{C}$, blocked endogenous peroxidase by $3 \%$ hydrogen peroxide, and sealed non-specific binding with
$1 \%$ bovine serum albumin, the sections were then incubated with the antibody against COL6A1 as primary antibody overnight at $4^{\circ} \mathrm{C}$. After washing, the sections were incubated with horseradish peroxidase-conjugated secondary antibody in the dark at room temperature for $30 \mathrm{~min}$ utes. Then the sections were washed and stained with 3,3'diaminobenzidine (DAB) (Sigma-Aldrich Co., St Louis, MO, USA). Finally, the sections were dehydrated and mounted, and pictures were taken by microscope for positive cell calculation. The intensity of stained cells was classified into four classes: 0 , no staining; 1, weak staining; 2, positive staining; and 3 , strong staining. The proportion of positively stained tumor cells was evaluated: 0 , $1,2,3$, and 4 according to no staining, positive staining in $<10 \%, 10 \% \sim 50 \%, 51 \% \sim 80 \%$, and $>80 \%$ of tumor cells, respectively. Then, based on the multiply of the intensity and positive cell scores, $0 \sim 3$ and $4 \sim 12$ were defined low expression and high expression, respectively.

\section{Statistical Analysis}

Statistical analyses were performed using SPSS version 25.0 software. Overall survival (OS) was plotted using the Kaplan-Meier method. Differences in OS were analyzed using the Log rank test. $\mathrm{p}<0.05$ was considered to be statistically significant.

\section{Results}

\section{Effect of Extracellular Glucose Levels on} the Clone Formation of PC Cancer Cells

To estimate the influence of different extracellular glucose levels on PC cancer cells, AsPC-1 and BxPC-3 were cultured with the high or low level of glucose, respectively. As shown in Figure 1, compared with the low level of glucose, the high level of glucose could obviously promote clone formation in both AsPC-1 and BxPC-3 (Figure 1A), and clone counts further demonstrated the significantly different effect (Figure 1B). The results from CCK-8 assay also demonstrated that the promotion of proliferation by hyperglycemia in both AsPC-1 (Figure 2A) and BxPC-3 (Figure 2B) PC cancer cells.

\section{Effect of Extracellular Glucose Levels on the Migration Ability of PC Cancer Cells}

In the Transwell assay, migrated cancer cells were counted under an inverted optical microscope. For AsPC-1 PC cancer cells, migrated cells per field view treated with the low and high level of glucose were 
A

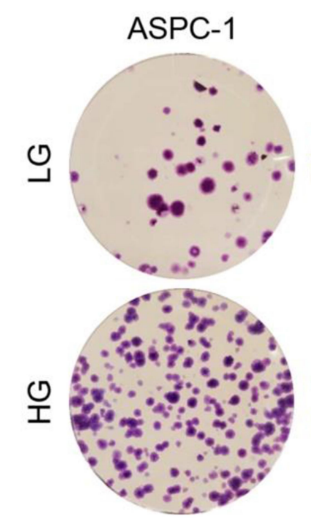

B

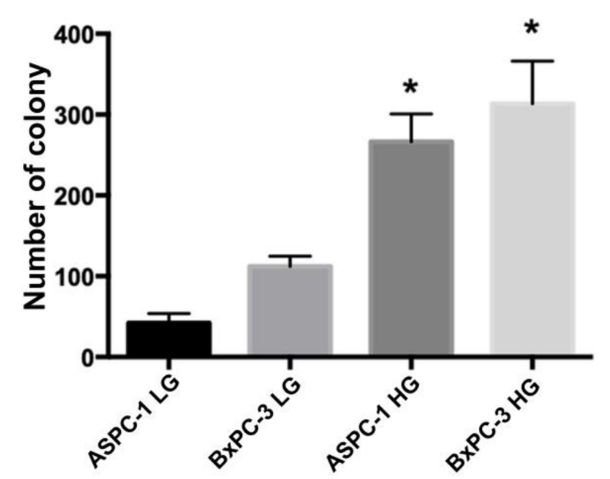

Figure I The clone formation of AsPC-I and BxPC-3 cancer cells cultured with the high or low level of glucose after I4 days. (A) Representative images of cell clone; (B) statistical analysis of clone counts. $* \mathrm{P}<0.05$.

Abbreviations: LG, low level of glucose; HG, high level of glucose.

$162 \pm 18$ and $570 \pm 63$, respectively. For BxPC-3 cancer cells, migrated cells per field view treated with the low and high level of glucose were $305 \pm 42$ and $810 \pm 113$, respectively. The significant increase in migrated cancer cells could be seen in both AsPC-1 and BxPC-3 treated with the high level of glucose than that of the low level of glucose (Figure 3).

\section{Regulated Expression of COL6AI in PC Cancer Cells Under Different Extracellular Glucose Levels}

Results of qRT-PCR demonstrated that expression of Col6al gene was upregulated in both AsPC-1 and BxPC-3 cancer cells cultured with the high level of glucose than that with the low level of glucose (Figure 4A). Compared with the low level of glucose, the high level of glucose could also cause significantly increased expression of COL6A1 protein in both AsPC-1 and BxPC-3 cancer cells, as determined by Western blotting (Figure 4B).

\section{The Level of COL6AI Expression in PC Patients with/without DM}

To further determine whether there was the difference in PC patients with/without DM, paraffin-embedded tissue samples underwent IHC analysis. The representative IHC of the low and high expression of COL6A1 in PC patients is shown in Figure 5. According to the scoring system, the level of COL6A1 expression between PC without DM and PC with DM were compared. As shown in Table 2, the results indicated that high COL6A1 expression was obviously observed among PC with DM compared with that of PC without DM.
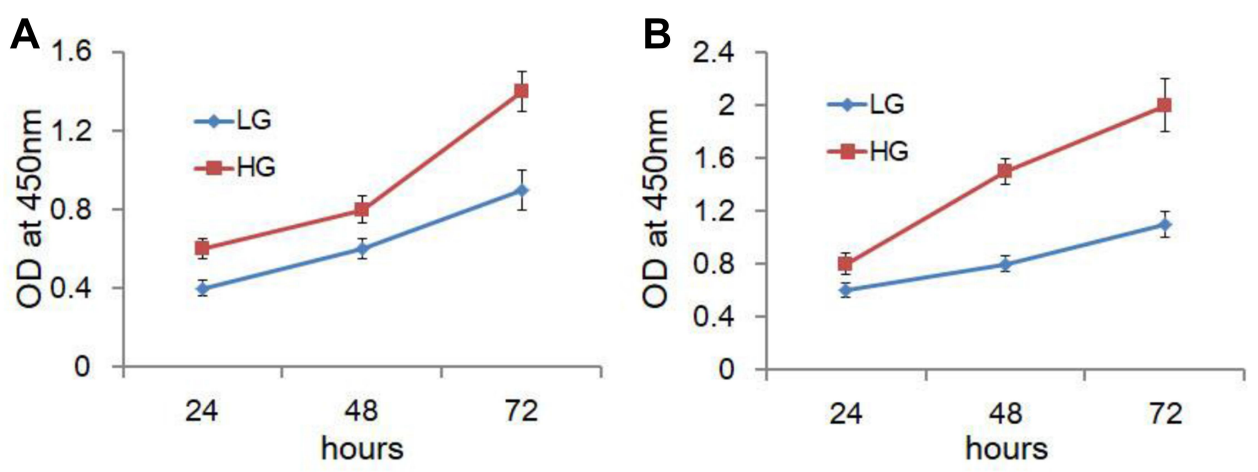

Figure 2 CCK-8 assay of AsPC-I and BxPC-3 cancer cells cultured with the high or low level of glucose. (A) AsPC-I cancer cell; (B) BxPC-3 cancer cell. Abbreviations: CCK-8, cell counting kit-8; OD, optical density; LG, low level of glucose; HG, high level of glucose. 


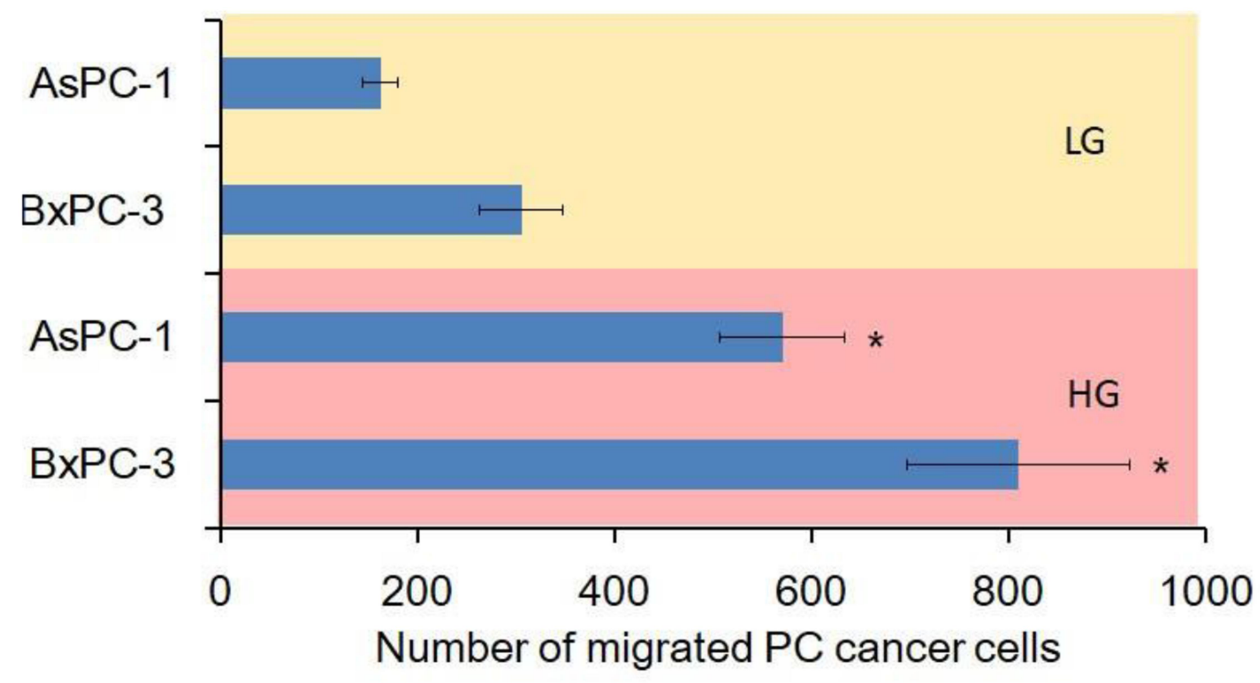

Figure 3 Migrated PC cancer cells treated with the low or high level of glucose in the Transwell assay. $* P<0.05$. Abbreviations: LG, low level of glucose; HG, high level of glucose; PC, pancreatic cancer.

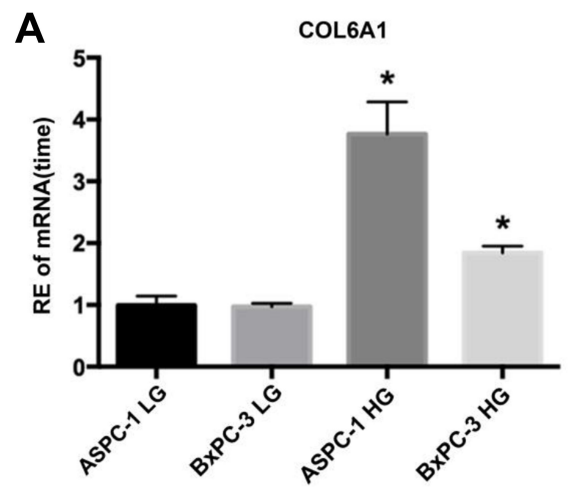

B

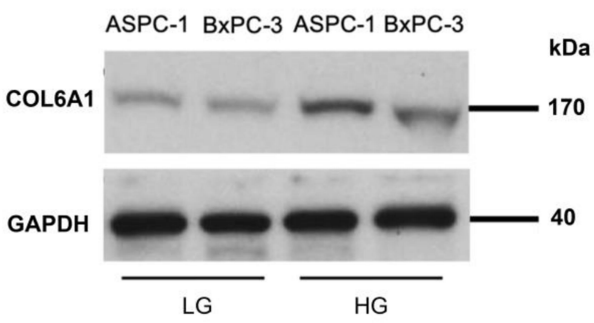

Figure 4 Expressions of Col6al gene and COL6AI protein in PC cancer cells under different extracellular glucose levels. (A) Expressions of Colbal gene; (B) Expressions of COL6AI protein. $* \mathrm{P}<0.05$.

Abbreviations: RE, relative expression; LG, low level of glucose; HG, high level of glucose; PC, pancreatic cancer.

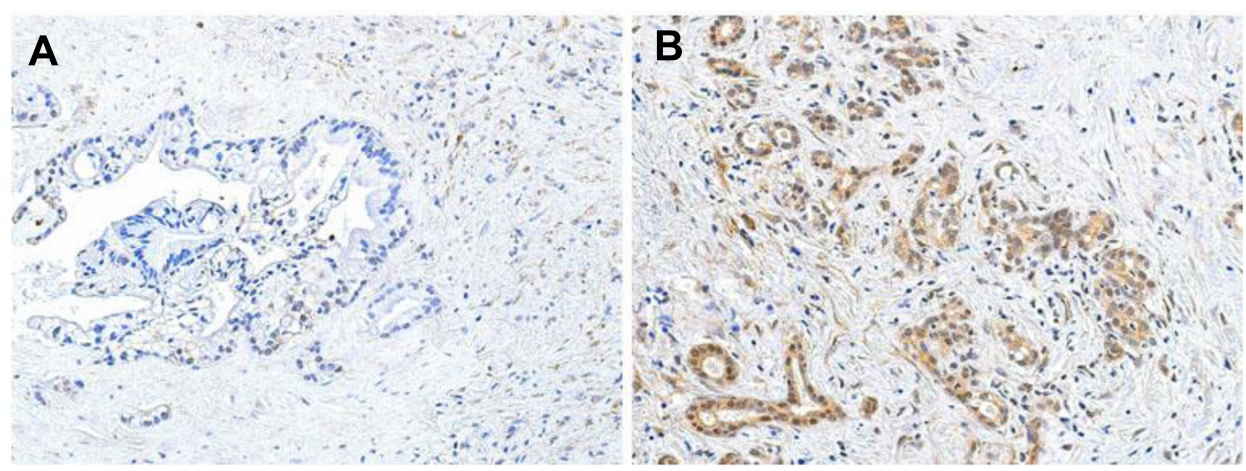

Figure 5 Representative immunohistochemical images of low and high expression of COL6AI in PC patient tissues. (A) Low expression of COL6AI in PC without DM; (B) high expression of COL6AI PC with DM.

Abbreviations: PC, pancreatic cancer; DM, diabetes mellitus. 
Table 2 The Level of COL6AI Expression Between PC Patients without/with DM

\begin{tabular}{|l|c|c|c|}
\hline Patient & $\begin{array}{c}\text { High Expression of } \\
\text { COL6AI }\end{array}$ & $\begin{array}{c}\text { Low Expression of } \\
\text { COL6AI }\end{array}$ & Total \\
\hline $\begin{array}{l}\text { PC with } \\
\text { DM }\end{array}$ & 22 & 38 & 60 \\
PC without & II & 55 & 66 \\
DM & 33 & 93 & 126 \\
Total & \multicolumn{2}{|c}{0.01} \\
\hline P value & \multicolumn{2}{|c}{} \\
\hline
\end{tabular}

Abbreviations: PC, pancreatic cancer; DM, diabetes mellitus.

\section{The Association Between COL6AI Expression and Clinical Outcomes in PC Patients with DM}

A total of 126 patients were confirmed for the analysis during the study period, including the group of PC with DM of 60 and the group of PC without DM of 66. The base line clinic characteristics of the two groups are presented in Table 3. There were no significant differences in age, gender and tumor stage. The prognostic impact of COL6A1 on PC patients with DM was assessed by Kaplan-Meier survival curve analysis. As shown in Figure 6, COL6A1 expression was significantly associated with the clinical prognosis of PC patients with DM. Patients with high expression of COL6A1 had significantly lower OS compared to those with low expression $(\mathrm{P}<0.05)$. The median OS in PC patients with DM for the high and low expression of COL6A1 was $13.5 \pm 3.0$ months and $23.5 \pm 5.1$ months, respectively.

Table 3 The Clinic Characteristics of PC with DM and PC without DM

\begin{tabular}{|l|c|c|c|c|}
\hline & & $\begin{array}{c}\text { PC with } \\
\text { DM }\end{array}$ & $\begin{array}{c}\text { PC without } \\
\text { DM }\end{array}$ & P value \\
\hline Gender & & & & 0.619 \\
& Male & 46 & 53 & \\
& Female & 14 & 13 & \\
\hline Age & & $58.85 \pm 7.22$ & $59.73 \pm 6.52$ & 0.543 \\
\hline TNM stage & & & & 0.61 \\
& I & 6 & 8 & \\
& II & II & I3 & \\
& III & 43 & 45 & \\
\hline
\end{tabular}

Abbreviations: PC, pancreatic cancer; DM, diabetes mellitus.

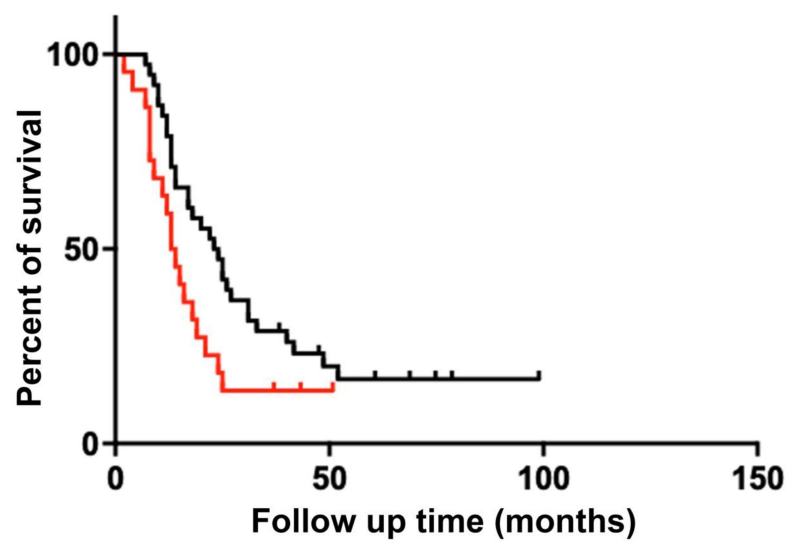

Figure 6 Kaplan-Meier curves of overall survival according to COL6AI expression in PC patients with DM.

Abbreviations: PC, pancreatic cancer; DM, diabetes mellitus.

\section{Discussion}

In this study, PC cancer cells could be affected by oscillating extracellular glucose level, of which the high level of glucose promoted their clone formation and migration property compared with the low level of glucose. Increased expressions of COL6A1 involved in the effect of high level of glucose on PC cancer cells, which could be the underlying molecular mechanism. From bench to clinical bed, the retrospective analysis from patients also indicated that higher COL6A1 expression was among PC patient with DM compared with that of PC without DM. What is more, COL6A1 acted as poorer prognosis factor for PC patient with DM, which was illustrated by that higher expression of COL6A1 contributed to significantly lower OS in PC patient with DM.

Abnormal glucose metabolism is closely related to $\mathrm{PC}^{23}$ Hyperglycemia can increase the activity of glyoxal reductase, and specifically activate polyol pathway such as PKC and $\mathrm{NF}-\lambda \mathrm{B}$, and promote carcinogenesis. ${ }^{24}$ Energy supply in tumor cells is mainly provided by anaerobic digestion, and hyperglycemia just can enhance cell anaerobic digestion and provide energy source for tumor cell growth. ${ }^{25}$ The longterm damage of normal pancreatic organelles by hyperglycemia could transform normal cells into tumor cells. ${ }^{26} \mathrm{In}$ this study, in vitro effect of different glucose levels on cancer cells further confirmed hyperglycemia could promote the development of PC. Extracellular matrix (ECM) in the tumor microenvironment is often haphazard and thus promotes the growth and migration of cancer cells. ${ }^{27}$ Collagen VI consisted of three major polypeptide chains $(\alpha 1, \alpha 2$ and $\alpha 3)$ is one of the main ECM. ${ }^{28}$ Among them, the $\alpha 1$ chain 
encoded by Col6al participated in multiple signaling pathways that regulate cell apoptosis, proliferation, angiogenesis, fibrosis, and inflammation. Studies showed that the expression of COL6A1 increased in tumors and associated with tumor progression. Voiles et al found a higher COL6A1 expression in lung tumor tissues, which may promote the development of tumor. ${ }^{29}$ Fujita et al reported that differential expression of COL6A1 among normal glial cells and different grades of glioma. ${ }^{30}$ Runt-related transcription factor 3 (Runx3) could activate expression of COL6A1 to increase metastasis in $\mathrm{PC}^{21}$ In our study, expression of both Col6almRNA and COL6A1 protein increased in PC cancer cells cultured with the high level of glucose than that with the low level of glucose. The results further revealed the potential role of COL6A1 in PC, especially PC with DM.

30-40\% PC patients have comorbid DM and 80\% PC patients have abnormal glucose tolerance. ${ }^{6,31}$ Although COL6A1 highly expressed in PC patients, ${ }^{16}$ its role in PC patients with DM remains unclear. In our study, we firstly expanded meaningful discoveries in PC patients with/without DM that high COL6A1 expression was obviously observed among PC with DM compared with PC without DM. In clinical researches, there were a few investigations reporting the prognostic impact of COL6A1 in several human cancers. Hou et al uncovered that COL6A1 was evidently related to the clinical prognosis of patients with cervical cancer. ${ }^{32}$ Wan et al found that COL6A1 upregulation predicted poor outcomes in clear cell renal cell carcinoma. ${ }^{33}$ Consistent with studies reporting a negative correlation between COL6A1 and prognostic impact, we further confirmed that patients with high expression of COL6A1 had obviously lower OS compared to those with low expression $(\mathrm{P}<0.05)$ in $\mathrm{PC}$ patients with $\mathrm{DM}$. This therefore reminds us of the importance of controlling blood glucose in PC patients with DM.

\section{Conclusions}

In conclusion, in vitro, the high level of extracellular glucose could promote proliferation, migration and invasion of PC cancer cells involved in up-regulated expression of COL6A1. In PC patients with DM, COL6A1 expression was higher compared with that of $\mathrm{PC}$ without DM. Besides, the clinical outcome of PC patients with DM was related to COL6A1 expression which acted as a poor prognostic biomarker. These findings suggested that COL6A1 could be as a predictive biomarker and therapeutic target, and to control blood glucose should be beneficial for PC patients with DM.

\section{Acknowledgments}

This work was supported by Nanjing Health Science and Technology Development Project (YKK18254).

\section{Disclosure}

The authors report no conflicts of interest in this work.

\section{References}

1. Siegel RL, Miller KD, Jemal A. Cancer statistics, 2017. CA Cancer J Clin. 2017;67(1):7-30. doi:10.3322/caac.21387

2. Cancer.Net. Pancreatic Cancer: Statistics. American Society of Clinical Oncology. ASCO; 2018.

3. Ferlay J, Colombet M, Soerjomataram I, et al. Estimating the global cancer incidence and mortality in 2018: GLOBOCAN sources and methods. Int $J$ Cancer. 2019;144(8):1941-1953. doi:10.1002/ ijc. 31937

4. Kleeff J, Costello E, Jackson R, et al. The impact of diabetes mellitus on survival following resection and adjuvant chemotherapy for pancreatic cancer. Br J Cancer. 2016;115(7):887-894. doi:10.1038/ bjc. 2016.277

5. Walter U, Kohlert T, Rahbari NN, Weitz J, Welsch T. Impact of preoperative diabetes on long-term survival after curative resection of pancreatic adenocarcinoma: a systematic review and meta-analysis. Ann Surg Oncol. 2014;21(4):1082-1089. doi:10.1245/s10434-0133415-6

6. Pannala R, Leirness JB, Bamlet WR, Basu A, Petersen GM, Chari ST. Prevalence and clinical profile of pancreatic cancer-associated diabetes mellitus. Gastroenterology. 2008;134(4):981-987. doi:10.1053/j.gastro.2008.01.039

7. Boursi B, Finkelman B, Giantonio BJ, et al. A clinical prediction model to assess risk for pancreatic cancer among patients with new-onset diabetes. Gastroenterology. 2017;152(4):840-850.e3. doi:10.1053/j.gastro.2016.11.046

8. Abudawood M. Diabetes and cancer: a comprehensive review. $J$ Res Med Sci. 2019;24(1):94. doi:10.4103/jrms.JRMS_242_19

9. Mizuno S, Nakai Y, Isayama H, et al. Diabetes is a useful diagnostic clue to improve the prognosis of pancreatic cancer. Pancreatology. 2013;13(3):285-289. doi:10.1016/j.pan.2013.03.013

10. Kaleru T, Vankeshwaram VK, Maheshwary A, Mohite D, Khan S. Diabetes mellitus in the middle-aged and elderly population $(>45$ years) and its association with pancreatic cancer: an updated review. Cureus. 2020;12(6):e8884. doi:10.7759/cureus. 8884

11. Harry K, Kein-Leong Y. Exploring the bi-directional relationship between pancreatic cancer and diabetes mellitus: a retrospective study. J Diabetes Metab Disord. 2018;17(2):247-252. doi:10.1007/ s40200-018-0366-2

12. Tan Z, Xu J, Zhang B, Shi S, Yu X, Liang C. Hypoxia: a barricade to conquer the pancreatic cancer. Cell Mol Life Sci. 2020;77 (16):3077-3083. doi:10.1007/s00018-019-03444-3

13. Onozuka H, Tsuchihara K, Esumi H. Hypoglycemic/hypoxic condition in vitro mimicking the tumor microenvironment markedly reduced the efficacy of anticancer drugs. Cancer Sci. 2011;102 (5):975-982. doi:10.1111/j.1349-7006.2011.01880.x

14. Uhlen M, Zhang C, Lee S, et al. A pathology atlas of the human cancer transcriptome. Science. 2017;357(6352):eaan2507. doi:10.1126/science.aan2507

15. Dassah M, Almeida D, Hahn R, Bonaldo P, Worgall S, Hajjar KA. Annexin A2 mediates secretion of collagen VI, pulmonary elasticity and apoptosis of bronchial epithelial cells. J Cell Sci. 2014;127 (4):828-844. doi:10.1242/jcs. 137802 
16. Owusu-Ansah KG, Song G, Chen R, et al. COL6A1 promotes metastasis and predicts poor prognosis in patients with pancreatic cancer. Int J Oncol. 2019;55(2):391-404. doi:10.3892/ijo.2019.4825

17. Pontén F, Jirström K, Uhlen M. The Human Protein Atlas-a tool for pathology. J Pathol. 2008;216(4):387-393. doi:10.1002/path.2440

18. Hou T, Tong C, Kazobinka G, et al. Expression of COL6A1 predicts prognosis in cervical cancer patients. Am J Transl Res. 2016;8 (6):2838-2844.

19. Zhu Y-P, Wan F-N, Shen Y-J, Wang H-K, Zhang G-M, Ye D-W. Reactive stroma component COL6A1 is upregulated in castration-resistant prostate cancer and promotes tumor growth. Oncotarget. 2015;6(16):14488-14496. doi:10.18632/oncotarget.3697

20. Chiu K-H, Chang Y-H, Wu Y-S, Lee S-H, Liao P-C. Quantitative secretome analysis reveals that COL6A1 is a metastasis-associated protein using stacking gel-aided purification combined with iTRAQ labeling. J Proteome Res. 2011;10(3):1110-1125. doi:10.1021/pr1008724

21. Jian Z, Cheng T, Zhang Z, et al. Glycemic variability promotes both local invasion and metastatic colonization by pancreatic ductal adenocarcinoma. Cell Mol Gastroenterol Hepatol. 2018;6 (4):429-449. doi:10.1016/j.jcmgh.2018.07.003

22. Livak KJ, Schmittgen TD. Analysis of relative gene expression data using real-time quantitative PCR and the $2-\Delta \Delta \mathrm{CT}$ Method. Methods. 2001;25(4):402-408. doi:10.1006/meth.2001.1262

23. Principe DR, Rana A. Updated risk factors to inform early pancreatic cancer screening and identify high risk patients. Cancer Lett. 2020;485:56-65. doi:10.1016/j.canlet.2020.04.022

24. Aleksandrovski YA. Molecular mechanisms of the cross-impact of pathological processes in combined diabetes and cancer. Research and clinical aspects. Biochemistry (Mosc). 2002;67(12):1329-1346. doi:10.1023/a:1021801808405
25. Schwartz L, Supuran CT, Alfarouk KO. The Warburg effect and the hallmarks of cancer. Anticancer Agents Med Chem. 2017;17 (2):164-170. doi:10.2174/1871520616666161031143301

26. Schwartz SS, Grant SFA, Herman ME. Intersections and clinical translations of diabetes mellitus with cancer promotion, progression and prognosis. Postgrad Med. 2019;131(8):597-606. doi:10.1080/ 00325481.2019.1657358

27. Hessmann E, Buchholz SM, Demir IE, et al. Microenvironmental determinants of pancreatic cancer. Physiol Rev. 2020;100 (4):1707-1751. doi:10.1152/physrev.00042.2019

28. Sato T, Takano R, Tokunaka K, et al. Type VI collagen $\alpha 1$ chain polypeptide in non-triple helical form is an alternative gene product of COL6A1. J Biochem. 2018;164(2):173-181. doi:10.1093/jb/ mvy040

29. Voiles L, Lewis DE, Han L, et al. Overexpression of type VI collagen in neoplastic lung tissues. Oncol Rep. 2014;32(5):1897-1904. doi:10.3892/or.2014.3438

30. Fujita A, Sato JR, Festa F, et al. Identification of COL6A1 as a differentially expressed gene in human astrocytomas. Genet Mol Res. 2008;7(2):371-378. doi:10.4238/vol7-2gmr432

31. Magruder JT, Elahi D, Andersen DK. Diabetes and pancreatic cancer: chicken or egg? Pancreas. 2011;40(3):339-351. doi:10.1097/ MPA.0b013e318209e05d

32. Hou T, Tong C, Kazobinka G, et al. Expression of COL6A1 predicts prognosis in cervical cancer patients. Am J Transl Res. 2019;8 (6):2838-2844.

33. Wan F, Wang H, Shen Y, et al. Upregulation of COL6A1 is predictive of poor prognosis in clear cell renal cell carcinoma patients. Oncotarget. 2015;6(29):27378-27387. doi:10.18632/oncotarget.4860

\section{Publish your work in this journal}

Cancer Management and Research is an international, peer-reviewed open access journal focusing on cancer research and the optimal use of preventative and integrated treatment interventions to achieve improved outcomes, enhanced survival and quality of life for the cancer patient.
The manuscript management system is completely online and includes a very quick and fair peer-review system, which is all easy to use. Visit http://www.dovepress.com/testimonials.php to read real quotes from published authors. 